\title{
ENSO Suppression due to Weakening of the North Atlantic Thermohaline Circulation*
}

\author{
A. Timmermann And S.-I. AN \\ IPRC, SOEST, University of Hawaii at Manoa, Honolulu, Hawaii \\ U. KREBS \\ Leibniz Institut für Meereswissenschaften, IfM-GEOMAR, Kiel, Germany \\ H. Goosse \\ Institut d'Astronomie et de Géophysique G. Lemaître, Université Catholique de Louvain, Louvain-la-Neuve, Belgium
}

(Manuscript received 10 November 2004, in final form 24 March 2005)

\begin{abstract}
Changes of the North Atlantic thermohaline circulation (THC) excite wave patterns that readjust the thermocline globally. This paper examines the impact of a freshwater-induced THC shutdown on the depth of the Pacific thermocline and its subsequent modification of the El Niño-Southern Oscillation (ENSO) variability using an intermediate-complexity global coupled atmosphere-ocean-sea ice model and an intermediate ENSO model, respectively. It is shown by performing a numerical eigenanalysis and transient simulations that a THC shutdown in the North Atlantic goes along with reduced ENSO variability because of a deepening of the zonal mean tropical Pacific thermocline. A transient simulation also exhibits abrupt changes of ENSO behavior, depending on the rate of THC change. The global oceanic wave adjustment mechanism is shown to play a key role also on multidecadal time scales. Simulated multidecadal global sea surface temperature (SST) patterns show a large degree of similarity with previous climate reconstructions, suggesting that the observed pan-oceanic variability on these time scales is brought about by oceanic waves and by atmospheric teleconnections.
\end{abstract}

\section{Introduction}

The response of the tropical climate to an anticipated greenhouse warming depends on many factors that have been explored only partially. It has been argued (Ramanathan and Collins 1992; Fu et al. 1992; Hartmann and Michelsen 1993; Sun and Liu 1996; Clement et al. 1996; Pierrehumbert 1995; Miller 1997) that both thermodynamical and dynamical thermostat effects (negative feedbacks) play an important role in controlling the temperature of the tropical Pacific with possible consequences for the amplitude of ENSO (Sun

\footnotetext{
* International Pacific Research Center Contribution Number 308 and School of Ocean and Earth Science and Technology Contribution Number 6540.
}

Corresponding author address: Dr. A. Timmermann, IPRC, SOEST, University of Hawaii at Manoa, 2525 Correa Road, Honolulu, HI 96822.

E-mail: axel@hawaii.edu
2003). On the other hand, future tropical temperature trends may be strongly determined by the vertical distribution of water vapor in the atmosphere and its potential to amplify surface temperature changes due to an enhanced trapping of longwave radiation within the lower layers of the atmosphere. A delicate balance between positive and negative feedbacks seems to determine the magnitude and pattern of greenhouse warming in the tropical Pacific. The associated uncertainty in our understanding of the processes is also reflected in the uncertainty of the coupled general circulation model (CGCM) projections for the twenty-first century (Collins 2000; Timmermann et al. 1999a). Some models such as a version of the Canadian Climate Model simulate a very strong warming of the tropical Pacific of about $7 \mathrm{~K}$ (Boer et al. 2004), whereas others generate a more modest warming behavior (Collins 2000) in response to a $\mathrm{CO}_{2}$ doubling.

A similar uncertainty can be found for the projected model behavior of the thermohaline circulation (THC) 
in the North Atlantic. Some greenhouse simulations (J. M. Oberhuber 1999, personal communication; Latif et al. 2000) exhibit a rather stable THC due to changes in the Atlantic-Pacific water vapor transport induced by a warming of the eastern equatorial Pacific, whereas other climate model simulations seem to operate closer to the saddle bifurcation point of the THC and are hence more sensitive to North Atlantic buoyancy changes (Houghton et al. 2001).

Modeling uncertainties in the tropical Pacific and of the THC response are also linked to each other, either via oceanic or atmospheric teleconnections. An atmospheric link between temperature variations in the eastern tropical Pacific and the stability of the thermohaline circulation was conjectured for the first time by Schmittner et al. (2000). The potential impact of THC changes on the El Niño-Southern Oscillation (ENSO) phenomenon transmitted also by large-scale atmospheric changes has been described briefly in Dong and Sutton (2002). In addition to atmospheric bridges that may communicate signals between the North Atlantic and the tropical Pacific, also oceanic waves-so-called oceanic seiches - can transfer thermocline signals from the North Atlantic to the tropical Pacific with potential impacts on ENSO variability (Goodman 2001; Cessi et al. 2004).

The Atlantic part of these seiches can in fact explain the millennial-scale dynamics of the north-south interhemispheric temperature contrast observed in ice cores during Marine Isotope Stage 3 (MIS3; 60 000-25 000 yr B.P.) as shown by Knutti et al. (2004). Based on a coupled global atmosphere-ocean-sea ice simulation for the Last Glacial Maximum, Timmermann et al. (2005) suggested that the observed millennial-scale synchronous behavior between Pacific warm pool salinity variations (Stott et al. 2002) and the so-called Dansgaard-Oeschger events (Dansgaard et al. 1993) in the North Atlantic can be attributed to global oceanic baroclinic waves triggered by glacial meltwater pulses in the North Atlantic [so-called Heinrich events (Heinrich 1988)]. Related geostrophic surface transport anomalies carry saline water to the North Pacific with implications for deep convection and the setup of a Pacific intermediate thermohaline circulation cell, in agreement with the modeling results of Saenko et al. (2004). Such a reorganization of the Pacific large-scale oceanic circulation may have important influences also for ENSO dynamics. This efficient oceanic global wave adjustment mechanism contrasts the recently proposed millennial-scale SuperENSO hypothesis (Stott et al. 2002), which suggests that millennial-scale tropical Pacific SST anomalies trigger changes in the atmospheric circulation with subsequent influence on North Atlantic climate, thereby leading to an atmospheric synchronization of Pacific and Atlantic climate change on millennial time scales.

Based on these considerations, the question arises whether a possible future decline of the meridional overturning circulation in the North Atlantic may have an influence on future ENSO variability, as speculated by Goodman (2001). This question becomes more urgent in the light of the recent observed freshening in the North Atlantic (Dickson et al. 2002).

Furthermore, interdecadal variability in the North Atlantic, as observed by Kushnir (1994), and Mann and Park (1994), and Mann et al. (1995) and as simulated using CGCMs (Delworth et al. 1993; Timmermann et al. 1998; Delworth and Mann 2000) may have an influence on the variance of ENSO, as conjectured by Timmermann (2003). In fact the R15 Geophysical Fluid Dynamics Laboratory (GFDL) coupled model (Delworth et al. 1993) exhibits a 50-80-yr THC mode and shows an amplitude modulation of the weak simulated ENSO with a similar time scale (Knutson et al. 1997). The same link can be observed in the ECHAM3/LSG model simulation as studied by Timmermann et al. (1998) and Timmermann et al. (1999b). Whether this is a coincidence or whether this behavior is a manifestation of a robust oceanic link between the North Atlantic and the tropical Pacific remains unclear (see footnote 1 of Timmermann 2003). Global seiches may provide a mechanism to connect multidecadal THC changes in the North Atlantic with climate anomalies in the Indian and Pacific oceans.

Our paper is organized as follows. After a brief introduction into the concept of global baroclinic ocean adjustment (section 2) and a description of the model (section 3) and experimental setup (section 4), we describe the simulated sensitivity of the global THC to centennial-freshwater changes in the North Atlantic (section 5). The thermocline background changes have a significant influence on the amplitude and other characteristics of ENSO, as discussed in section 6. In section 7 , the results from a periodic North Atlantic freshwater forcing experiment are compared with reconstructed multidecadal variability. Section 8 summarizes our main results, and a discussion of the relevance of our results concludes this study.

\section{Global baroclinic ocean adjustment}

The oceanic connection between the North Atlantic and tropical Pacific mentioned above works as follows: Density changes in the North Atlantic lead to a global readjustment of the thermohaline circulation. This readjustment is established by the propagation of coastally and equatorially trapped Kelvin waves (Wajsowicz 


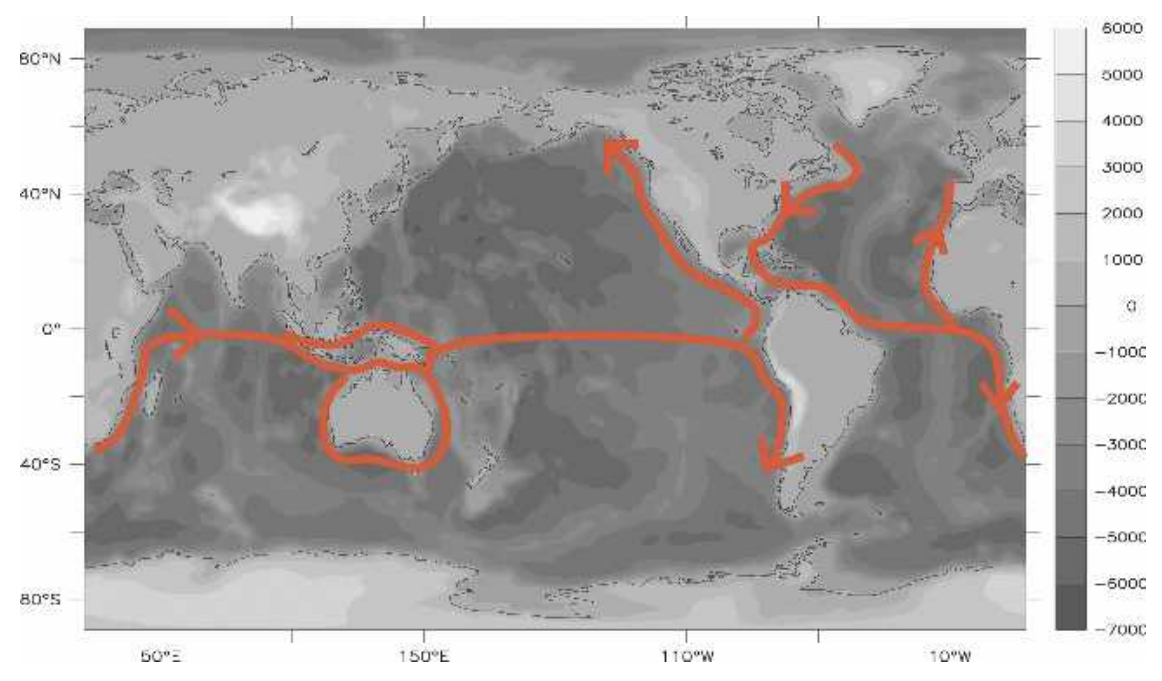

FIG. 1. Schematics of Kelvin wave propagation due to a density perturbation in the northeastern North Atlantic.

1986; Kawase 1987; Suginohara and Fuakasawa 1988; Döscher et al. 1994; Goodman 2001; Hsieh and Bryan 1996; Huang et al. 2000; Johnson and Marshall 2002; Cessi et al. 2004; Johnson and Marshall 2004) and shelf waves (Mysak 1980). After propagating from the North Atlantic to the equator, these waves are forced to travel along the equator toward the coast of Africa, where they split into a northern and southern branch. While moving poleward, they radiate Rossby waves, which readjust the interior transport of the North and South Atlantic after reaching the western boundary. The southern wave branch travels around the southern tip of South Africa into the Indian Ocean and subsequently the Pacific Ocean. Important stages of the global baroclinic adjustment process to an initial North Atlantic density anomaly take place within a few years to decades (Cessi et al. 2004), whereas a very fast intertiagravity wave signal can be traced in the Pacific even months after the initial North Atlantic buoyancy shock. The overall baroclinic adjustment time scale can be decomposed into a fast North Atlantic time scale and a long adjustment time scale of the other oceans with the Atlantic equatorial buffer zone separating the propagation features of the adjusting waves (Johnson and Marshall 2002) and the Antarctic Circumpolar Current delaying the complete global adjustment further by centuries due to low Rossby wave speeds. The overall sea level and thermocline depth changes can be described in terms of a standing wave pattern - a global seiche (Cessi et al. 2004). This wave adjustment mechanism is schematized in Fig. 1.

In coarse-resolution ocean models, the waves that establish the overall mass balance are represented by viscous boundary waves (Hsieh et al. 1983). Their char- acteristics depend partially on the numerical schemes employed by the ocean model and differ somewhat from those of free Kelvin waves. Furthermore, the amplitude $e$-folding time depends on the vertical and lateral viscosity of the numerical model (Kawase 1987) and on the grid resolution. The ratio between Rossby wave shedding and viscous boundary wave propagation depends crucially on the viscosity of numerical models (Kawase 1987). This implies also that the amplitude of long-term transport variability in the Atlantic may be dependent on the numerical representation of viscosity. This is an overlooked feature with implications for the interpretation of simulated interdecadal climate variability in the North Atlantic (Delworth et al. 1993; Timmermann et al. 1998).

It is obvious that the signal reaching the Pacific Ocean must be significantly smaller than the initial Kelvin wave signal in the North Atlantic, because of the energy loss of radiating Rossby waves. Still, on interdecadal to millennial time scales, this mechanism may provide quite an efficient link between the North Atlantic and the Pacific. The efficiency of this seiching mechanism on interannual to interdecadal time scales has been discussed by Johnson and Marshall (2004) using an idealized reduced-gravity shallow-water model, driven by periodic pressure forcing in the North Atlantic. The equations for the efficiency of the eastern boundary thermocline responses in adjacent ocean basins read (Johnson and Marshall 2004)

$$
\frac{P}{I}=\frac{\frac{g^{\prime} H}{f_{p}}}{\frac{g^{\prime} H}{f_{p}}-\int_{\phi_{p}}^{\phi_{N}} R c\left[1-e^{-i \omega l_{p} / c}\right] d \phi}
$$




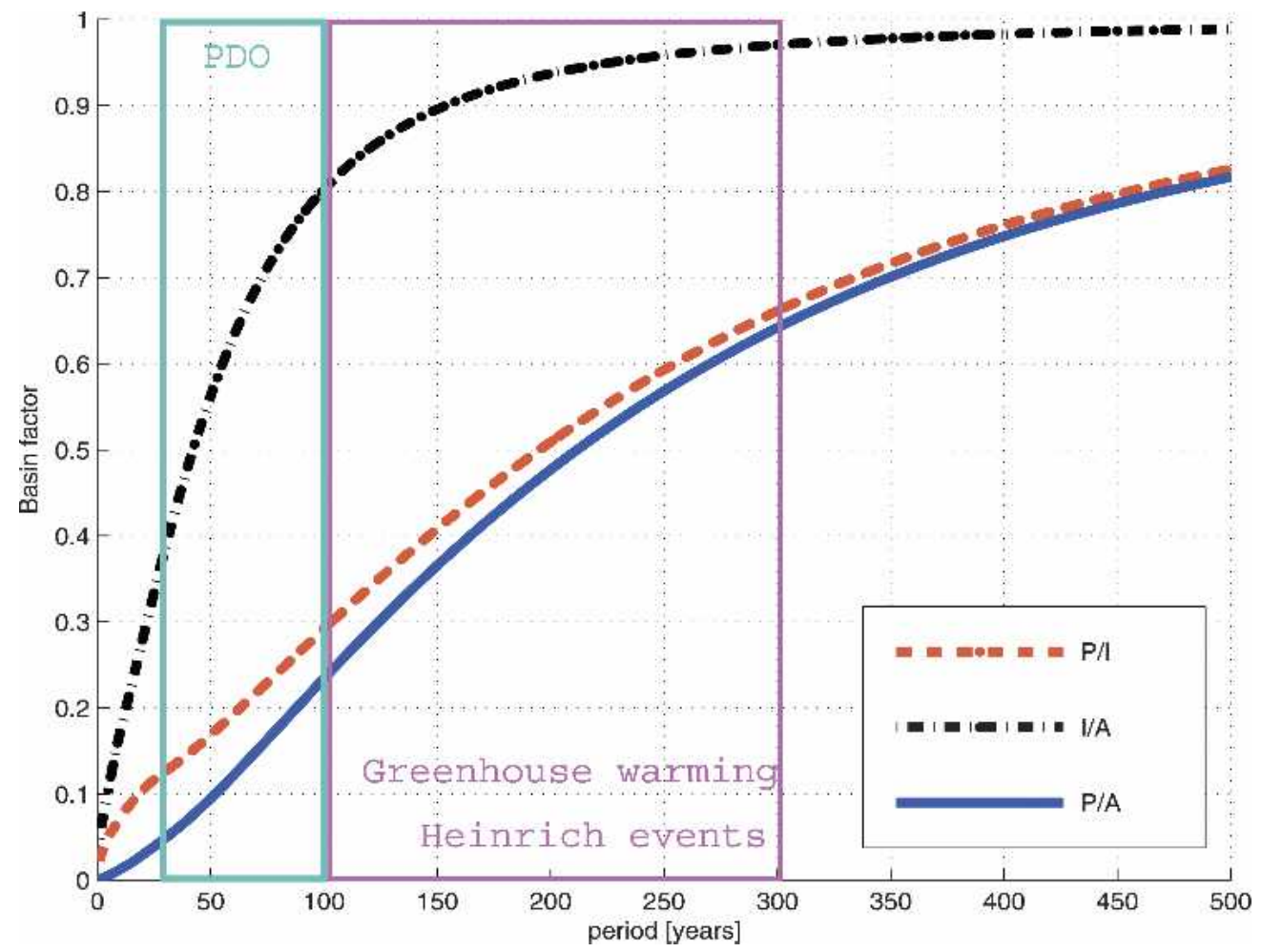

FIG. 2. Amplitude ratio of eastern equatorial basin thermocline anomalies as a function of forcing period in the northwestern North Atlantic. I/A, I/P, and P/A denote the Indian-Atlantic, the Indian-Pacific, and Pacific-Atlantic ratios. The figure is obtained from Eqs. (1) and (2) using a reduced-gravity shallow-water model and neglecting friction, intertial processes, and nonlinearities near the eastern boundaries. It is assumed that the pressure at the eastern boundary in each basin is homogenized. Typical time scales for the PDO and Heinrich events as well as for greenhouse warming are marked by cyan and magenta frames, respectively.

$$
\frac{I}{A}=\frac{\frac{g^{\prime} H}{f_{i}}}{\frac{g^{\prime} H}{f_{i}}-\int_{\phi_{i}}^{\phi_{N}} R c\left[1-e^{-i \omega l_{i} / c}\right] d \phi},
$$

where $g^{\prime}, H, c, \phi_{p}, \phi_{N}, \phi_{i}$, and $R$ represent the reduced gravity (0.1), the depth of the active thermocline layer (500 $\mathrm{m})$, the latitude-dependent baroclinic first Rossby wave speed, the latitude of Tasmania $\left(45^{\circ} \mathrm{S}\right)$, the latitude of the northern North Atlantic $\left(65^{\circ} \mathrm{N}\right)$, the latitude of Cape Good Hope $\left(36^{\circ} \mathrm{S}\right)$, and the earth's radius $\left(6.373 \times 10^{6} \mathrm{~m}\right)$, respectively; $f_{i}$ and $f_{p}$ are the respective Coriolis parameters for the latitudes $\phi_{i}$ and $\phi_{p}$, which are latitudinally dependent widths of the Pacific and Indian Oceans. Using these equations, we have extended the time-scale range up to $500 \mathrm{yr}$ (Fig. 2).

Neglecting the role of inertial terms, nonlinearity, and friction, it is found that eastern boundary thermocline depth anomalies in the Atlantic Ocean can be transmitted efficiently to the Indian and Pacific Oceans on time scales longer than $50 \mathrm{yr}$. On time scales typical for Heinrich events (and greenhouse warming), about
$30 \%-60 \%$ of the Atlantic thermocline depth amplitude at the eastern boundary is transmitted into the Pacific Ocean by the wave adjustment mechanism discussed above, thereby providing a very strong pan-oceanic teleconnection mechanism on centennial and millennial time scales, which may contribute to the generation of glacial millennial-scale variability in the Indian (Schultz et al. 1998) and Pacific Oceans (Stott et al. 2002; Behl and Kennett 1996).

\section{Models}

The aim of this study is to quantify the influence of THC variations in the North Atlantic on the thermocline structure in the equatorial Pacific and its potential influence on ENSO characteristics. A freshwater perturbation experiment is performed with the coupled global atmosphere-ocean sea ice model of intermediate complexity, ECBILT-CLIO (Timmermann et al. 2004; Knutti et al. 2004), to study the influence of a THC shutdown on the global thermocline structure. 
This coarse-resolution model is not able to simulate ENSO-like variability because of the low resolution of the atmospheric and oceanic model and the quasigeostrophic assumption employed for the atmosphere. The Bjerknes coupled air-sea feedback (Bjerknes 1969) is too weak (Timmermann et al. 2004) to amplify SST anomalies considerably. To address how the triggered thermocline changes influence ENSO variability, we use an intermediate ENSO model, similar to the Zebiak and Cane (1987) model that simulates ENSO realistically, for a present-day climate background state. This prescribed background state will be modified according to the ECBILT-CLIO modeling results to be discussed below. Eigenanalysis as well as transient simulations with the ENSO model (An et al. 2004) will be performed to shed light onto the sensitivity of ENSO to a North Atlantic THC collapse.

\section{a. Intermediate global coupled atmosphere-ocean model: ECBILT-CLIO}

We performed a series of global atmosphere-oceansea ice model simulations, with the coupled model of intermediate complexity, ECBILT-CLIO. The atmospheric component ECBILT (Opsteegh et al. 1998) of our coupled model is a three-layer model with a quasigeostrophic adiabatic core (Marshall and Molteni 1993) and a set of physical parameterizations for the hydrological cycle (Held and Suarez 1978) and a partly linearized radiation code. It employs a T21 triangular truncation, which corresponds to an approximate resolution of $5.6^{\circ}$ in both latitude and longitude. The coupled ocean-sea ice model CLIO (Goosse et al. 1999) is based on the primitive equations for the ocean using a free surface and thermodynamic/dynamic assumptions for the sea ice, respectively. A parameterization of vertical mixing (Goosse and Fichefet 1999) that represents a simplification of (Mellor and Yamada 1982) a 2.5-level turbulence closure scheme is used. Furthermore, the ocean model CLIO includes mixing along isopycnals, and it captures the effect of mesoscale eddies on the transport (Gent and McWilliams 1990). In addition, a bottom boundary layer scheme has been implemented to capture densewater overflows more appropriately (Campin and Goosse 1999). The horizontal resolution of CLIO is $3^{\circ}$, and there are 20 unevenly spaced vertical levels in the ocean. The equations of motion are solved on a B-grid (Mesinger and Arakawa 1976), with potential effects on the propagation characteristics of Kelvin waves (Hsieh et al. 1983). The individual models are coupled by exchanging momentum, fresh water, and heat.

\section{b. Intermediate ENSO model}

Our intermediate model is similar to the intermediate ENSO model of Zebiak and Cane (1987). The ocean model uses a 1.5-layer reduced-gravity model, a surface layer model capturing frictional processes and the Ekman layer, and an equation for the mixed layer temperature anomalies. The intermediate model is used in the anomaly mode, that is, prognostic equations are solved for the anomaly with respect to a given annual mean background state (in our case the observational background state for the currents, the mean thermocline depth, the mean temperature and the winds plus some background state perturbations to some of these quantities as explained below).

In contrast to the original Zebiak and Cane (1987) model, our model uses smoothed versions of the subsurface temperature parameterization, vertical advection, and the convergence feedback. The ocean dynamic equations are expanded in terms of Hermitian polynomials (Battisti 1988) in order to reduce the degrees of freedom of our system. Furthermore, an improved advection scheme has been used that treats the horizontal advection of temperature anomalies properly. The atmospheric model Gill (1980) is solved explicitly rather than iteratively. This leads to regular ENSO oscillations with a moderate skewness, in contrast to the highly chaotic and strongly skewed oscillations of the Zebiak and Cane (1987) model. ${ }^{1}$ Overall, the period of the ENSO oscillation in both model versions is similar.

Schematically the dynamical equations for our ENSO model can be written as

$$
\dot{\mathbf{x}}=\mathbf{F}(\mathbf{x}),
$$

$\mathbf{x}$ represents the state vector of currents, SST, and thermocline depth (expressed in terms of the spectral coefficients), and $\dot{\mathbf{x}}$ represents the time derivative of the state vector. The state vector is separated into a mean and an anomaly part $\mathbf{x}=\overline{\mathbf{x}}+\mathbf{x}^{\prime}$. Assuming the anomalies to be small with respect to the mean values, we can linearize the equations with respect to the timeindependent mean state $\overline{\mathrm{x}}$, which gives the first term of the Taylor expansion as follows:

$$
\dot{\mathbf{x}}^{\prime}=\left.\frac{\partial \mathbf{F}}{\partial \mathbf{x}}\right|_{\mathbf{x}=\overline{\mathbf{x}}} \mathbf{x}^{\prime}=\mathbf{A} \mathbf{x}^{\prime},
$$

where A represents the Jacobian matrix for a given background state $\overline{\mathbf{x}}$. For different climate background

\footnotetext{
${ }^{1}$ The highly chaotic nature of the Zebiak-Cane model originates from the numerical scheme of the atmosphere, which excites coupled dynamics.
} 
conditions, we compute the Jacobian matrix using a perturbation method in which the matrix elements are computed from small variable perturbations and their simulated corresponding time derivatives. As will be shown in a forthcoming paper, this method is very robust and approximates the Jacobian matrix quite well. In our case the size of the Jacobian matrix is $1439 \times$ 1439. Eventually, the eigenmodes of $\mathbf{A}$ for a given background state are computed. Using the ansatz $\mathbf{x}^{\prime}=$ $\sum_{j=1}^{1439} \mathbf{b}_{j} e^{i \omega_{j} t}$, we obtain the following set of algebraic equations:

$$
i \omega_{j} \mathbf{b}_{j}=\mathbf{A} \mathbf{b}_{j},
$$

which will be solved using standard numerical eigenanalysis techniques. The eigenmodes represent the most important dynamical features of the coupled ENSO model. Their spatial patterns (eigenvectors) can be associated with physical processes (see below); their real and imaginary eigenvalues characterize the growth and frequency of the corresponding eigenvector. A real part larger than zero corresponds to a growing mode that needs to be damped by nonlinearities; one with negative eigenvalues is damped and needs external energy sources to generate variability.

In many fluid-dynamical systems, the estimation of eigenmodes can be difficult, because small errors in the matrix estimation may give rise to large errors of the eigenvalues, as a result of the nonnormality of the linear operators. This effect can be quantified by using pseudospectral methods (Trefethen 1999), that provide uncertainty bounds for the linear eigenmodes. To show that our eigenmode solutions are robust, we have also computed the pseudospectra (Trefethen 1999) of the Jacobian matrix. The results (not shown here) indicate that small errors in the computation of the matrix elements of a few percent do not modify the eigenspectrum of the leading modes significantly, despite the nonnormality of the tropical coupled atmosphereocean system.

\section{Experimental setup}

\section{a. Control experiment for glacial maximum conditions}

The ECBILT-CLIO last glacial maximum (LGM) simulation performed here utilizes the (Peltier 1994) ice sheet topography, an ice sheet-albedo mask, reduced $\mathrm{CO}_{2}$ concentrations (200 ppm), modified orbital forcing, and an LGM vegetation index (Crowley and Baum 1997) for which the deforested soils and plant cover are replaced by their respective glacial albedos. The inclusion of the ice sheet increases the albedo by more than
$60 \%$ in North America and Europe. The associated changes of the river runoff and sea level drop have not been included here.

\section{b. Freshwater perturbation experiment for glacial maximum conditions}

At the core of our analysis is a transient glacial meltwater (MW) experiment, which simulates the response of the global climate to a North Atlantic density perturbation, such as, for instance, Heinrich Event II (23 ka ago). A 300-yr-long ${ }^{2}$ Gaussian-shaped freshwater anomaly is injected into the North Atlantic between $40^{\circ}$ and $60^{\circ} \mathrm{N}$ (see Fig. 3). The equivalent global sea level rise of this hydrological forcing amounts to about $8 \mathrm{~m}$.

As discussed in Timmermann et al. (2004) the transient glacial meltwater pulse experiment leads to an almost complete shutdown of the North Atlantic meridional overturning circulation (Fig. 3), a cooling of the North Atlantic by about $8-12 \mathrm{~K}$ with respect to the unperturbed LGM state and a complete recovery about $350 \mathrm{yr}$ after the anomalous freshwater forcing has been decreased to zero. As shown by Knutti et al. (2004), the MW experiment simulates a bipolar seesaw response, similar to the reconstructed north-south temperature gradient during Heinrich events (Blunier et al. 1998; Blunier and Brook 2001; Schmittner et al. 2003; Stocker and Johnsen 2003).

\section{Global seiching}

The thermohaline circulation transports relatively cold water into the deep ocean. This cold water upwells into the thermocline as a result of mixing and entrainment processes. This balance can be disrupted by a freshwater-induced halt of North Atlantic Deep Water formation. Eventually, the thermocline will deepen in the world oceans because of the reduced supply of cold water from below. This new equilibrium state is partly established by an adiabatic adjustment process that involves the propagation of Kelvin and Rossby waves (Kawase 1987; Suginohara and Fuakasawa 1988; Wajsowicz 1986; Döscher et al. 1994; Goodman 2001; Hsieh and Bryan 1996; Huang et al. 2000; Johnson and Marshall 2002; Cessi et al. 2004; Johnson and Marshall 2004). Here we use the depth of the $26 \mathrm{~kg} \mathrm{~m}^{-3}$ isopycnal to trace the induced global thermocline changes in the MW simulation, being well aware that the $\sigma_{\theta}-26$ surface does not represent the true thermocline every-

\footnotetext{
${ }^{2}$ Although Heinrich events occurred every 7-10 ka during the last glacial period, their duration was probably much shorter (in the order of a few hundred to thousand years).
} 


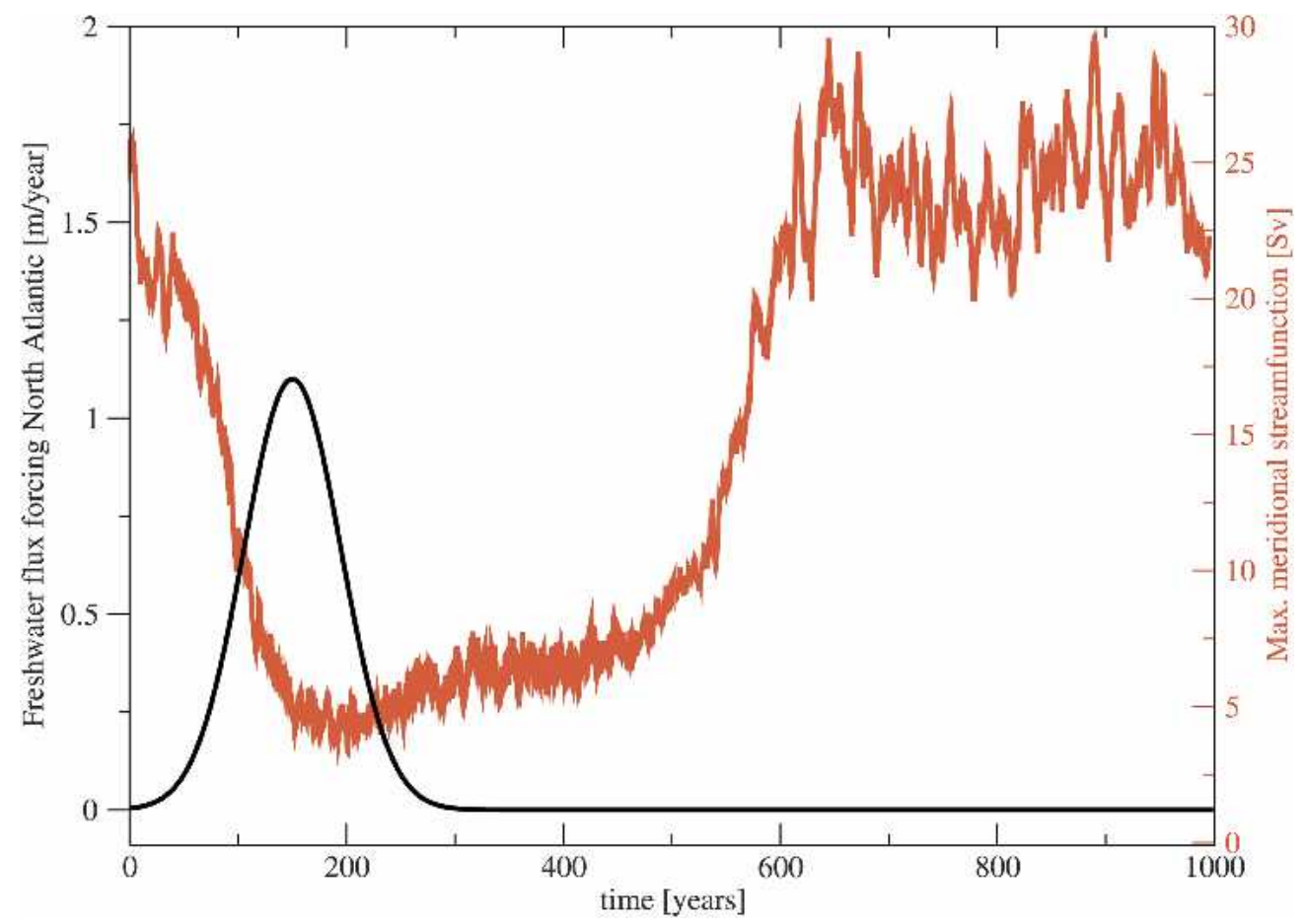

FIG. 3. Maximum of the meridional streamfunction (red) (in Sv) in the North Atlantic for the transient freshwater experiment MW and freshwater flux $\left(\mathrm{m} \mathrm{yr}^{-1}\right)$ forcing averaged over the North Atlantic from $40^{\circ}$ to $60^{\circ} \mathrm{N}$.

where. Our results are insensitive to reasonable choices of the $\sigma_{\theta}$ surface. As can be seen in Fig. 4, North Atlantic density changes modify the depth of the $\sigma_{\theta}-26$ surface worldwide. In addition to an overall thermocline deepening in the North Atlantic of about 60 $100 \mathrm{~m}$, we observe a deepening in the tropical Indian and Pacific Oceans by up to $20 \mathrm{~m}$, which is comparable to warm pool thermocline depth anomalies typically obtained during present-day ENSO events.

The overall thermocline anomaly pattern is comparable to that obtained from numerical simulations with reduced-gravity (Hsieh and Bryan 1996; Huang et al. 2000; Cessi et al. 2004; Johnson and Marshall 2004) and primitive equation models (Goodman 2001), except for the equatorial east-west thermocline gradient and the shoaling of the equatorial thermocline relative to the off-equatorial regions in the Pacific. The discrepancies between these idealized simulations and our coupled model simulation may originate from higher-order baroclinic processes or air-sea coupling, The study of Johnson and Marshall (2004) also revealed that the amplitude in the Pacific crucially depends on the forcing time scale of the North Atlantic density perturbations [see Eqs. (1) and (2)]. A North Atlantic forcing period of about $150 \mathrm{yr}$ can generate Pacific thermocline changes that attain amplitudes of $15 \%-30 \%$ of the North Atlantic thermocline changes (see Fig. 2). Although based on idealized assumptions, this theoretical estimate is in agreement with our complex modeling result. The thermocline response to a THC shutdown in our model (Fig. 4) is associated with geostrophic transport anomalies that lead to an enhancement of the South Equatorial Current and hence a transport of relatively cold and salty water to the western equatorial Pacific warm pool (Timmermann et al. 2005). It should be noted here that this does not hold for the uncoupled reduced-gravity-layer model simulations, which miss the zonal equatorial thermocline asymmetry.

Furthermore, in the North Pacific a geostrophic transport of anomalously saline water triggers deep convection in the Sea of Okhotsk. In turn this initiates a weak North Pacific intermediate overturning cell, as shown in Timmermann et al. (2005), thereby establishing a kind of Atlantic-Pacific THC seesaw (Saenko et al. 2004).

\section{THC influence on ENSO}

The simulated thermocline depth anomalies during the THC shutdown (Fig. 4) may have the potential 

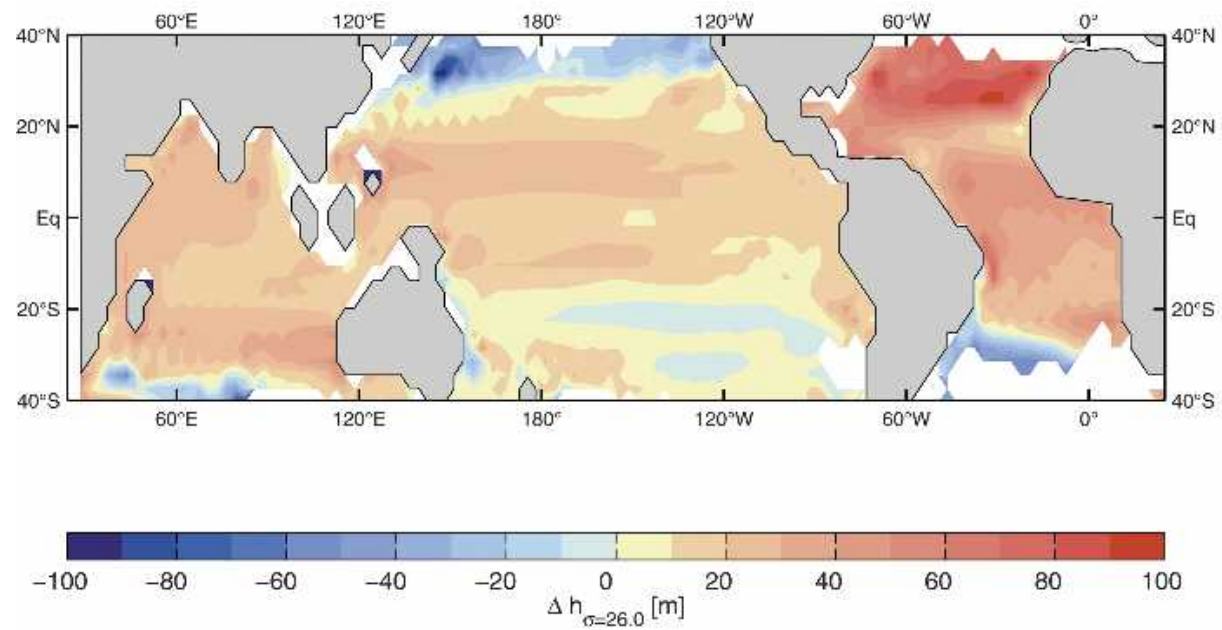

FIG. 4. Difference of the time-averaged depth of the isopycnal $26.0 \mathrm{~kg} \mathrm{~m}^{-3}$ surface between a collapsed THC state (years 200-300 in MW) and an uncollapsed LGM THC state (years 1-30 in $\mathrm{MW}$ ). The $26.0 \mathrm{~kg} \mathrm{~m}^{-3}$ isopycnal surface separates upper-ocean thermocline waters from deep ocean waters. An overall deepening of the North Atlantic thermocline is accompanied by a deepening of the thermocline in the other tropical oceans, whereas the subtropical areas and the eastern equatorial Pacific are characterized by a shoaling of the interface between upper and deep ocean. This pattern bears some similarities with the results of idealized modeling experiments (Huang et al. 2000; Cessi et al. 2004).

to change the properties of ENSO, as speculated by Goodman (2001). A mean equatorial and offequatorial deepening are expected to reduce ENSO instability as suggested by An et al. (2004). Here an eigenanalysis of the tropical background state is performed using the perturbation technique mentioned above and discussed in detail in An et al. (2004). The leading eigenmode (Figs. 5 and 6, top) of the presentday background state is the interannual recharge ENSO mode with stationary SST anomalies and zonal mean thermocline variations leading the SST anomalies by $90^{\circ}$ ( $\mathrm{Jin}$ 1997). The recharge mode works as follows: a positive SST anomaly in the eastern equatorial Pacific (El Niño) is associated with a wind stress curl that leads to a Sverdrup transport of warm thermocline water out of the equatorial Pacific. Eventually, the zonal mean thermocline shoals (see Fig. 6). Mean upwelling becomes more favorable and the positive Bjerknes feedback generates a La Niña event, which in turn pumps relatively warm water back into the equatorial thermocline due to changes in the off-equatorial wind stress curl, thereby recharging the system for the subsequent El Niño event.

Accounting only for the THC-induced tropical thermocline anomalies leads to significant changes in the stability of the ENSO eigenmode. The leading eigenmode switches its stability from unstable (no thermocline perturbation) to stable (negative growth rate; see green circle in Fig. 5, left). The frequency hardly changes relative to the unperturbed background state. Moreover, the propagation characteristics of the ENSO mode hardly change, except for a slight tendency for westward propagation in the eastern equatorial Pacific (see Fig. 6).

Changes of the damped scattering modes shall not be discussed here. This result implies that a THC shutdown and the subsequent overall deepening of the thermocline lead to a considerable damping of ENSO amplitude. It is likely that the details of the equatorial Pacific thermocline depth anomaly triggered by the THC weakening are different in different model simulations. In fact, the UVIC model (A. Schmittner 2004, personal communication) shows a zonal mean deepening of the equatorial Pacific thermocline of less than $5 \mathrm{~m}$. The zonal asymmetry simulated by the UVIC model has a different structure as compared to the ECBILT-CLIO results shown in Fig. 4. To test the robustness of our results with respect to the zonal asymmetry of the thermocline pattern, we have repeated an eigenanalysis of the intermediate ENSO model using only the zonal mean thermocline depth change of Fig. 4, neglecting any zonal asymmetries. The change of the stability of the leading ENSO eigenmode (not shown) is almost indistinguishable from that obtained for the full thermocline field (Fig. 5). The mechanism for this type of ENSO suppression 

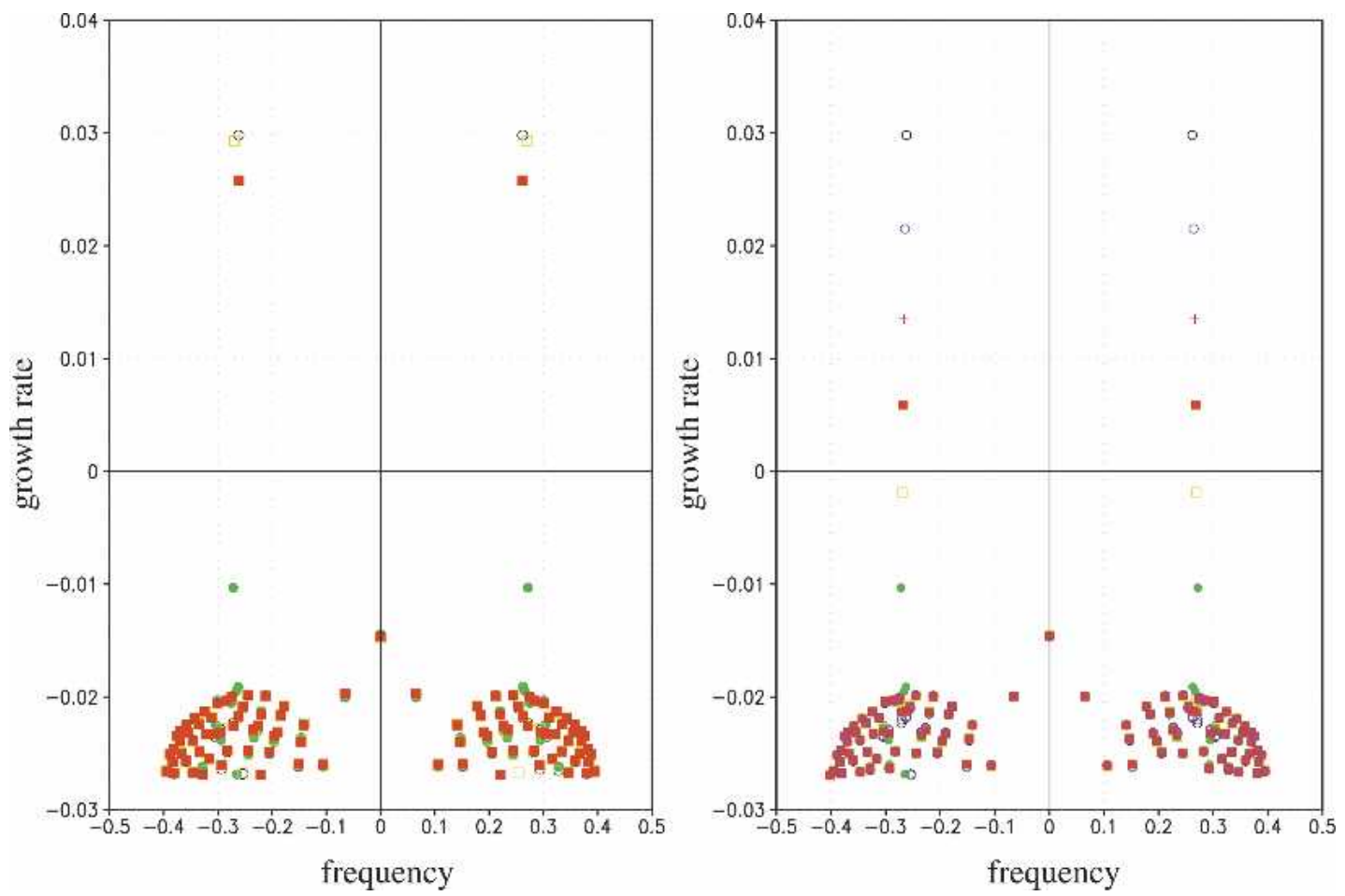

FIG. 5. (left) Real ( $y$ axis) and imaginary parts ( $x$ axis) of the eigenmodes of the control simulation (black circle) and the sensitivity experiments [thermocline (green circle), vertical temperature gradient (yellow square), and vertical velocity (red square)]. The real part is a measure for the growth rate of the eigenmodes $\left(1 \mathrm{yr}^{-1} \times 3 \pi^{-1}\right)$, whereas the imaginary part characterizes the frequency of the eigensolutions $\left(1 \mathrm{yr}^{-1} \times 3 \pi^{-1}\right)$. (right) Same as in left, but using different strengths of the thermocline perturbation (see Fig. 4) [0.2 (purple circle), 0.4 (red plus), 0.6 (red square), 0.8 (yellow circle), and 1.0 (green circle)]. The damped scatter modes in the lower part of the figures are free planetary wave modes that satisfy the given boundary condition of no net mass flow along the western boundary and the longwave approximation for a given spectral truncation (Liu 2002b).

works as follows: a negative zonal wind stress anomaly applied to an ocean characterized by a deep mean thermocline is less efficient in pumping up cold subthermocline water into the mixed layer than for a shallow mean thermocline. Hence, the thermocline feedback is less efficient for a deep mean thermocline than for a shallow one. This illustrates that a mean zonal thermocline deepening in the equatorial Pacific is responsible for the observed ENSO suppression. The zonal asymmetries that differ among different model simulations are only of secondary importance. These results are consistent with the sensitivity experiments of $\mathrm{Ze}$ biak and Cane (1987).

Furthermore, we have tested the stability of ENSO with respect to background changes of other variables. Accounting only for background state changes in the simulated vertical velocity (red square in Fig. 5, left) and the vertical temperature gradient (orange square in Fig. 5, left) does not change the ENSO stability diagram considerably. We performed further eigenanalysis of the intermediate ENSO model by modifying the amplitude of the thermocline background (including zonal mean and asymmetry) state anomaly by $20 \%, 40 \%$, $60 \%, 80 \%$, and $100 \%$ (Fig. 4). Figure 5 shows an almost linear decrease of the growth rate of the leading ENSO eigenmode with respect to the thermocline perturbation amplitude. Furthermore, theoretical studies of Johnson and Marshall (2004) reveal that also the amplitude of the zonal mean thermocline anomalies in the equatorial Pacific scales linearly with the initial thermocline depth change in the North Atlantic. Hence, the stability of ENSO (as quantified by the growth rate of the leading eigenmode) can be expressed to a first order as a monotonous (not necessarily linear) function of the freshwater flux anomaly injected into the North Atlantic.

Including all oceanic background changes simultaneously in our eigenanalysis (Fig. 7) reveals that the Pacific thermocline anomalies triggered by the THC shutdown still play the dominant role in damping 


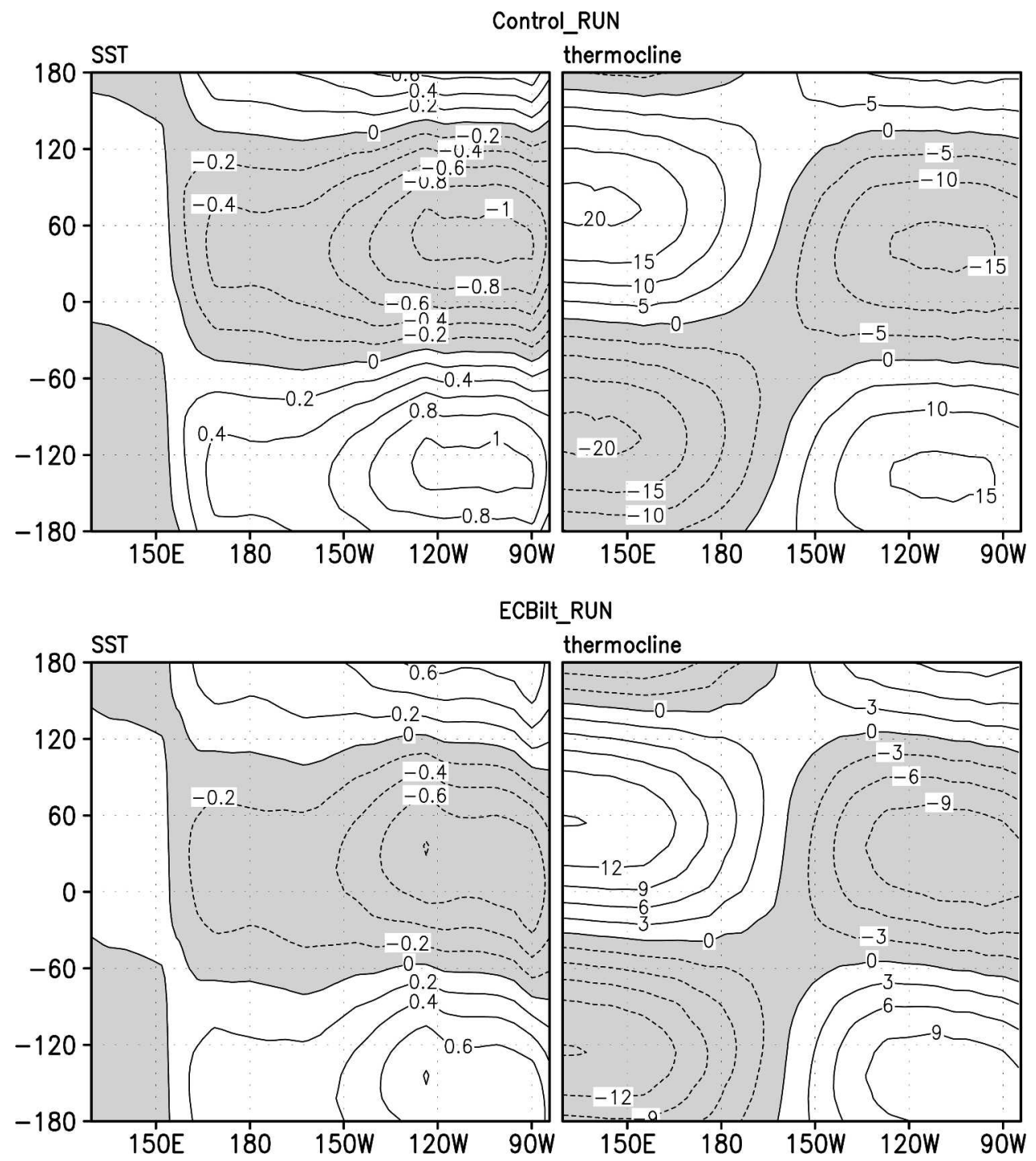

FIG. 6. Hovmoeller diagram of the leading eigenvector of the linearized Zebiak and Cane-type intermediate ENSO model for (top) observed present-day and (bottom) perturbed thermocline background conditions simulated by the MW experiment. Only the SST and thermocline depth averaged over $5^{\circ} \mathrm{S}-5^{\circ} \mathrm{N}$ are displayed. The time evolution represented by the phase on the $y$ axes is directed upward. The change of the growth rate is disregarded in this figure.

ENSO growth rate and hence in stabilizing ENSO variability.

An eigenanalysis does not take into account nonlinear damping, and it is not straightforward to link the stability of the leading eigenmodes to the amplitude of ENSO as simulated in a time integration. Here we will complement the eigenanalysis of ENSO by performing a forward simulation of the deterministic intermediate ENSO model forced by transient changes of the thermocline depth anomaly, as simulated by the ECBILT-CLIO MW experiment. In this transient simulation, a diagnosed smoothed (running mean of 5 yr) tropical Pacific thermocline depth anomaly from the
ECBILT-CLIO MW experiment is added each year to the prescribed observed annual mean background state $^{3}$ of the intermediate ENSO model domain. The thermocline depth anomaly is computed as the differ-

\footnotetext{
${ }^{3}$ Our coupled atmosphere-ocean sea ice model underestimates the Bjerknes feedback by a factor of 2-3. Furthermore, because of the coarse resolution, the equatorial undercurrent is not represented realistically. Hence the simulated time-mean thermocline depth does not provide a realistic starting point for an ENSO instability analysis. Thus, we have chosen the observed time-mean background state and the simulated anomalies as starting points of our analysis, following basically the philosophy of an anomaly coupled model.
} 


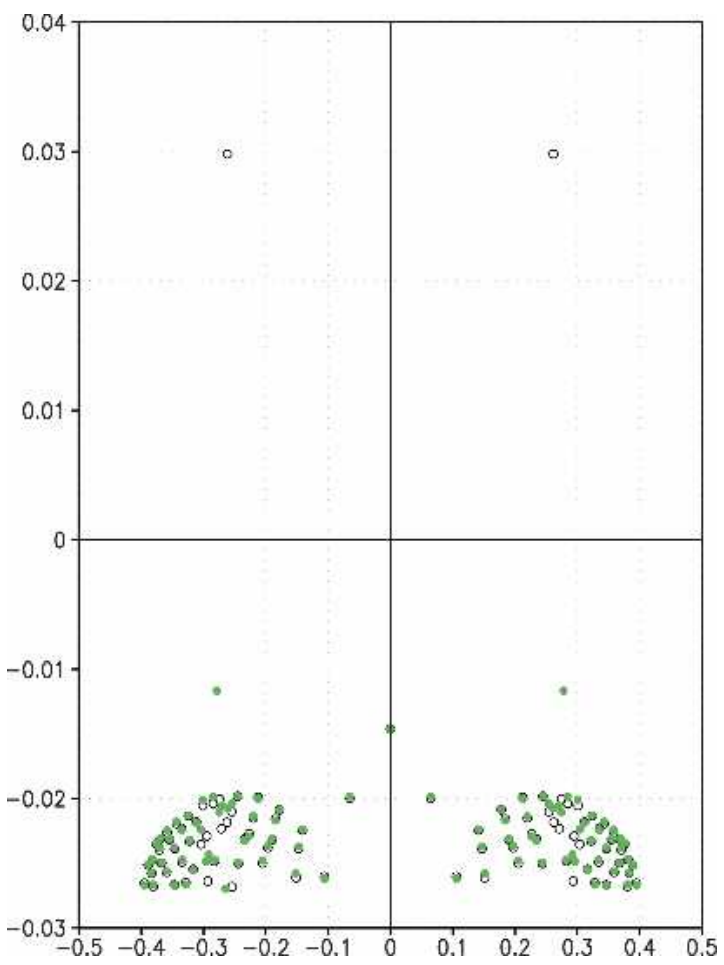

FIG. 7. Real ( $y$ axis) and imaginary parts ( $x$ axis) of the eigenmodes of the control simulation (black circles) and the experiment including the joint effect of changes in thermocline depth, vertical velocity, and temperature gradient (green circles).

ence of the depth of the $\sigma_{\theta}-26$ surface with respect to the control LGM experiment performed with ECBILTCLIO. We have not considered changes of the other background state variables such as SST, current, and wind changes since they have been shown to be only of minor importance for changing ENSO stability during the THC collapse.

The transient simulation results are depicted in Fig. 8 for three different thermocline forcing amplitudes $(1 / 3$, $2 / 3$, and the full amplitude, as shown in Fig. 4). The unperturbed ENSO (years 800-900) is characterized by a 4-5-yr periodicity and regular, slightly skewed oscillations (El Niño amplitude is larger than La Niña amplitude). For relatively large thermocline depths, weak and strong El Niño events alternate at the time scale of 4-5 yr, whereas large El Niño events occur only once in about 9-10 yr. The intermediate ENSO model used here does not simulate the observed irregularity of ENSO due to a lack of stochastic and annual cycle forcing. Furthermore, it neglects higher-order baroclinic modes as well as extratropical influences. In Fig. 8 we observe that a complete shutdown of the North Atlantic THC (Fig. 3) leads to a complete shutdown of ENSO variability. Smaller thermocline depth anomalies (Fig. 8 , top and middle) have an influence on spectral char- acteristics of ENSO but not so much on the amplitude of the self-sustained ENSO oscillation. This result, however, depends crucially on the atmosphere-ocean coupling strength used by the intermediate ENSO model. This parameter controls the stability of ENSO. Reducing the coupling strength to values closer to the Hopf bifurcation point makes ENSO characteristics more vulnerable to background state changes. Choosing smaller coupling coefficients $(\mu=0.9$ and 0.85$)$ than used in the previous simulations ( $\mu=1$; Fig. 8), even one-third of the MW thermocline depth change is sufficient to reduce ENSO variability very significantly in the transient simulation (see Fig. 9).

Because of the skewness of ENSO, variance changes (Fig. 8) are also associated with changes in the climate mean state in the eastern tropical Pacific, as shown in Clement et al. (1999) and Timmermann (2003). Here the thermocline-induced decrease in ENSO amplitude in the intermediate ENSO model leads to an overall cooling of the eastern equatorial Pacific by about $0.4 \mathrm{~K}$.

The results presented in this section are quite robust, even if the MW experiment is performed under preindustrial rather than LGM conditions. This leads to the conclusion that a possible future weakening of the thermohaline circulation due to greenhouse warming (Houghton et al. 2001) may lead to a weakening of future ENSO variability. We are, however, aware of the fact that there are many other controlling factors that determine the amplitude of ENSO, such as the direct greenhouse warming effect, the equatorial thermocline sharpness (Timmermann et al. 1999a; Meehl et al. 2001), nonlinear dynamic heating (Jin et al. 2003; An and Jin 2004), changes in the strength of the annual cycle (Liu 2002a; Timmermann and Jin 2004), or offequatorial SST anomalies (Collins 2000).

\section{Interdecadal THC variability}

An additional experiment has been performed with the ECBILT-CLIO for preindustrial conditions in which periodic freshwater forcing of about $0.4 \mathrm{~Sv}$ (1 Sv $\equiv 10^{6} \mathrm{~m}^{3} \mathrm{~s}^{-1}$; maximum amplitude) is applied to the North Atlantic between $40^{\circ}$ and $60^{\circ}$ with a 35 -yr period. The resulting time series of the meridional overturning index (maximum of the meridional streamfunction in the North Atlantic; not shown) exhibits variations on a 35 -yr-long time scale with an amplitude of $\pm 7.5 \mathrm{~Sv}$. These variations trigger also variations of the SST in the North Atlantic, the Indian Ocean, and the Pacific Ocean. To quantify the global impacts of multidecadal THC variations, we computed the linear regression between a smoothed North Atlantic SST index (running average of $7 \mathrm{yr}$ ) and the global field of annual mean 
a.

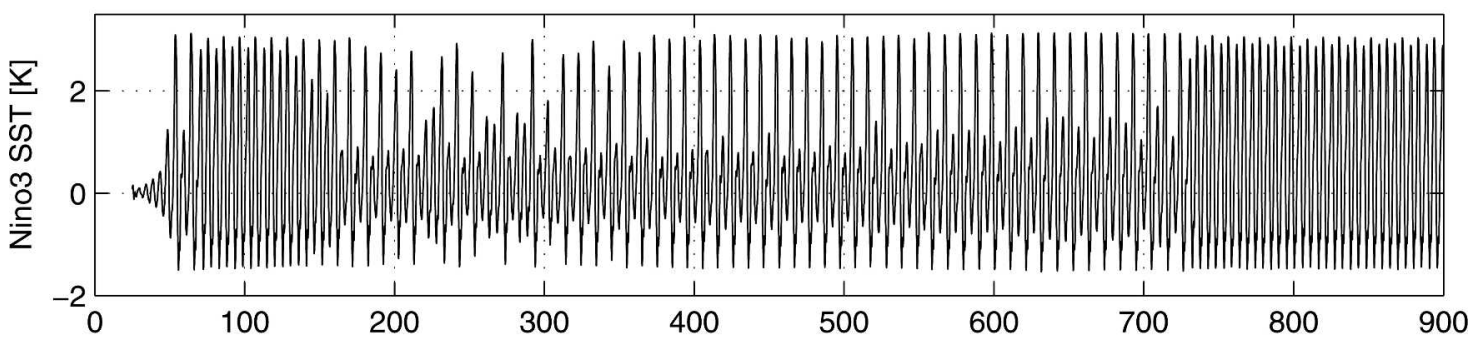

b.

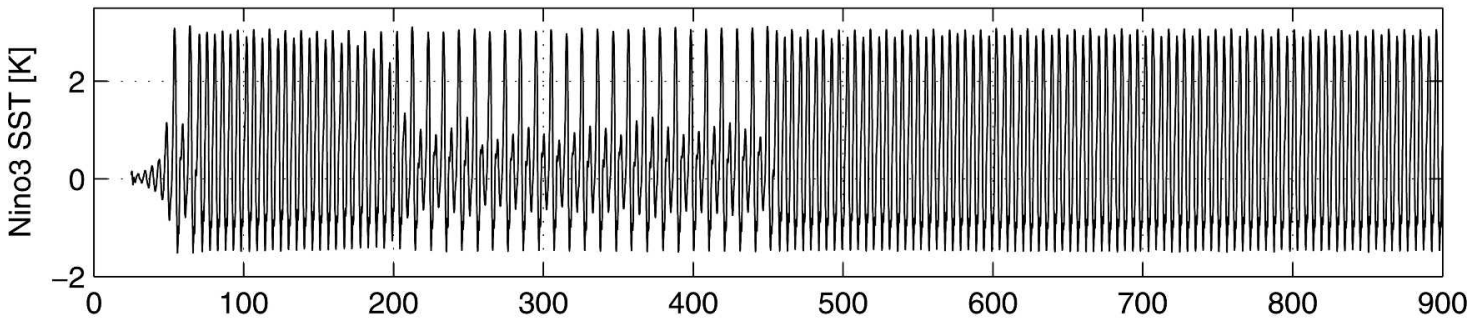

C.

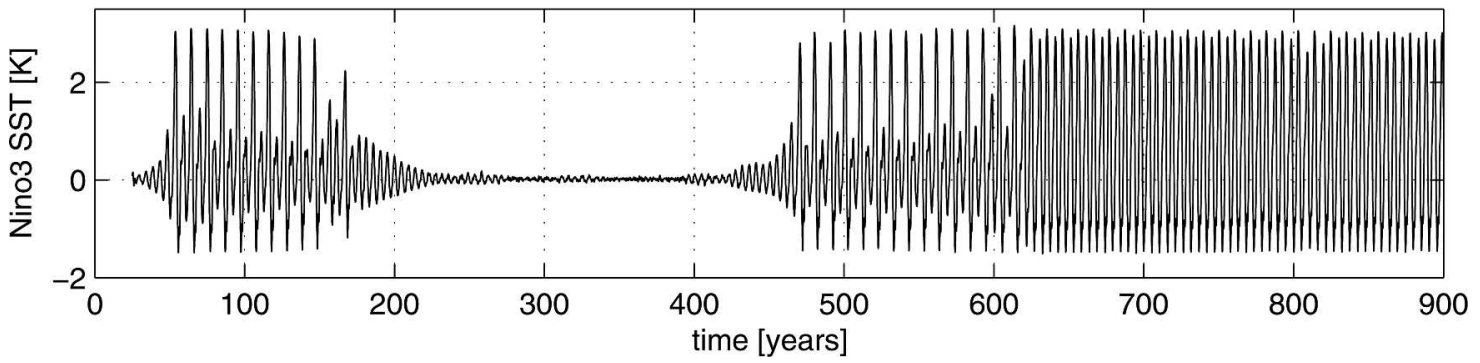

FIG. 8. Transient response of ENSO to THC-induced changes: Niño-3 SST anomaly (SSTA) time series (K) simulated by the intermediate ENSO model. The background thermocline depth is updated every year, such as to capture the spatiotemporal behavior of thermocline changes in the MW experiment. The simulation uses (top) one-third of the MW thermocline perturbation, (middle) two-thirds of the perturbation, and (bottom) the full thermocline anomaly. These different perturbations correspond to a 6-, 12-, and 18-Sv change of the maximum of the meridional streamfunction in the North Atlantic.

temperatures for different lags (expressed in terms of phase degrees of the forcing period). We observe (Fig. 10) a 35-yr cycle not only in North Atlantic SST but also in the Southern Hemispheric temperatures and also in the Indian Ocean and the equatorial and North Pacific. An increase of the meridional overturing circulation (phase -60-0) leads to a warming of the North Atlantic and a cooling of the Southern Hemisphere, as already discussed by Knutti et al. (2004), brought about by dynamic and thermodynamic processes involving also the global wave adjustment discussed in previous sections. Furthermore, we observe that the North Pacific zonal temperature dipole (phase -90-0) changes phase in response to the North Atlantic freshwater forcing. The decrease of the meridional overturning (phase 30-60) is accompanied by a spreading of the cold waters in the Southern Hemisphere, leading to an overall cooling of the Indian Ocean, the South Atlantic, and the equatorial and northeastern Pacific. These global SST anomalies are partly generated by the global wave adjustment process discussed above. Contributions from the atmospheric response to North Atlantic SST anomalies may also contribute to the pan-oceanic SST pattern. The relatively large temperature anomalies in the Kuroshio are due to a meridional displacement of a sharp temperature front in our model. A coastal Kelvin wave near the coast of California generates Rossby waves that propagate to the western boundary, where they lead to an adjustment of the transports. Eventually this leads to a meridional displacement of the Kuroshio front and hence the development of relatively strong temperature anomalies in this region.

Similar global-scale decadal-multidecadal variations of SST have been observed in previous CGCM simula- 

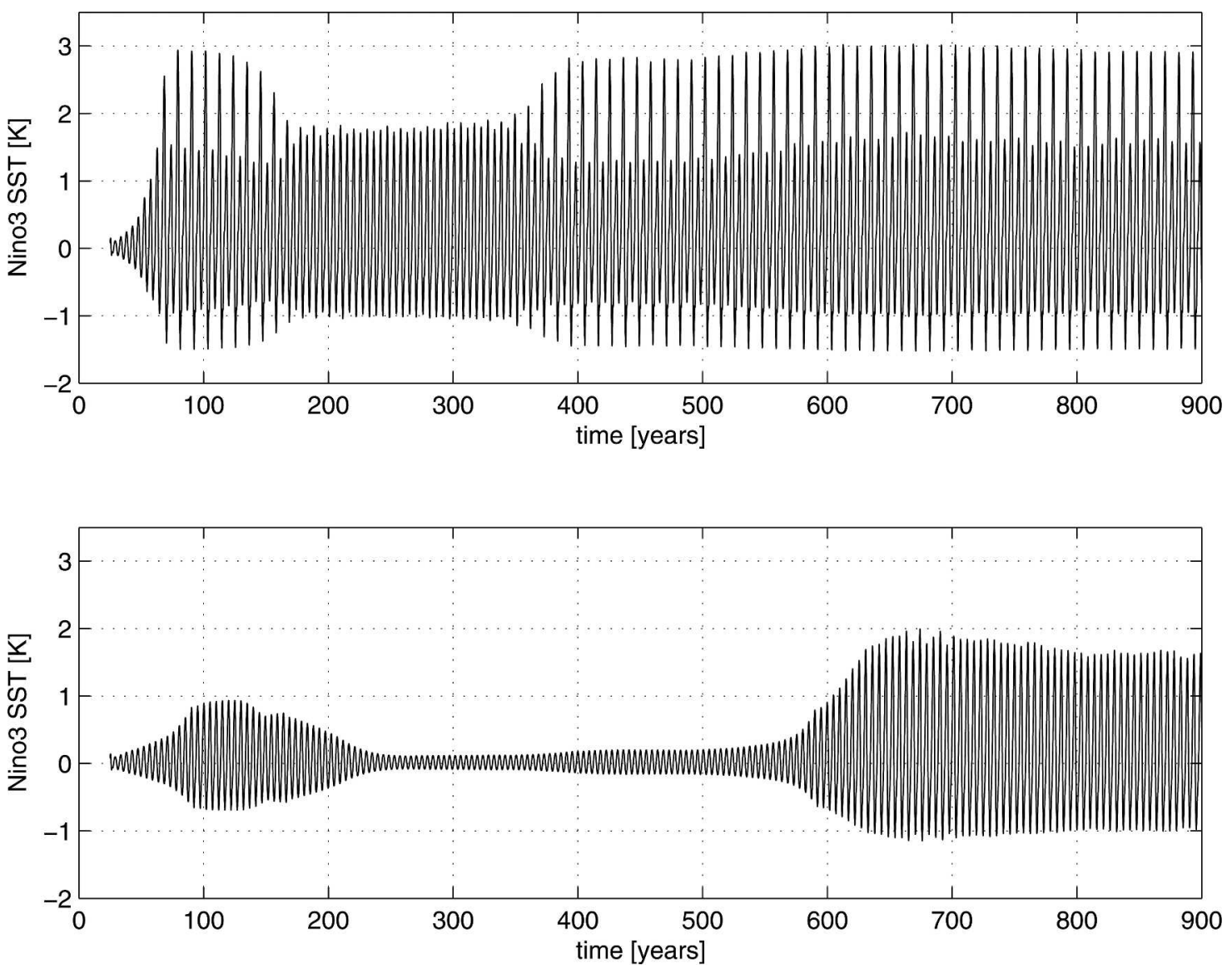

FIG. 9. Same as in Fig. 8, but the simulations use one-third of the MW thermocline perturbation and a coupling strength of (top) 0.9 and (bottom) 0.85 .

tions (Timmermann et al. 1998; Meehl et al. 1998; Delworth and Mann 2000). Without going further into the details of the adjustment process for this 35 -yr forcing experiment, we would like to stress here that the simulated pan-oceanic connections shown in Fig. 10 exhibit a large degree of similarity with recent reconstructions of multidecadal climate modes during the last $300 \mathrm{yr}$ (Fig. 5 in Delworth and Mann 2000). According to the mechanism discussed here, a deep equatorial Pacific thermocline (phase 30-60) is accompanied by weaker ENSO variability. Whether the observed weakening of ENSO during the 1930-60 period can be explained in terms of the multidecadal mode (triggered by North Atlantic THC variations) being in a phase less favorable (deep equatorial Pacific thermocline) for ENSO activity still remains to be shown.

To illustrate the sensitivity of ENSO to interdecadal thermohaline forcing in the North Atlantic, we performed a sensitivity experiment with the intermediate ENSO model. The background state thermocline depth of the ENSO model is updated every single year, such as to account for the thermocline anomalies (obtained from the depth of changes of the 25-isopycnal) simulated by the ECBILT-CLIO freshwater experiment. The results are shown in Fig. 11. A weakening of the thermohaline circulation in the North Atlantic (Fig. 11, top) is associated with a deepening of the tropical Pacific about 20-25 yr later (Fig. 11, middle), which is in rough accordance with the theoretical results of Johnson and Marshall (2004, their Fig. 13b). The zonal mean thermocline depth in the tropical Pacific undergoes variations of several meters, which is comparable in magnitude to previous modeling estimates on decadal-interdecadal time scales. A deepening of the thermocline leads to a subsequent weakening of El Niño events (Fig. 11, bottom) and an overall reduction of ENSO variance. Shallow thermocline situations correlate with a preferred occurrence of strong El Niño events. Even interdecadal changes of the thermohaline circulation in the North Atlantic may have some weak impact on ENSO variability. Given the relatively weak ENSO response and the fact that the propagation of 

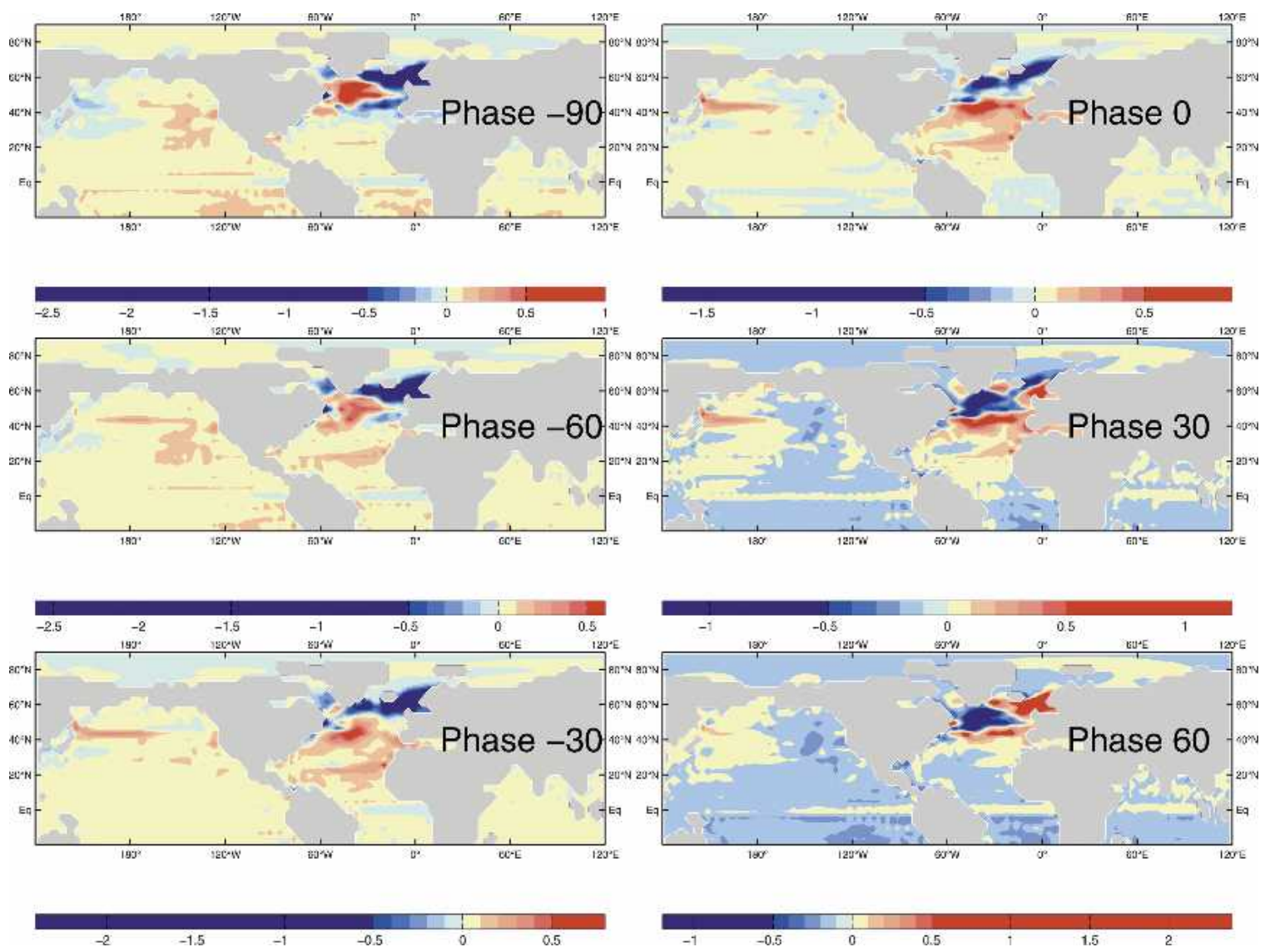

FIG. 10. Regression of North Atlantic SST averaged from $0^{\circ}$ to $50^{\circ} \mathrm{N}$ and $60^{\circ} \mathrm{W}$ to $10^{\circ} \mathrm{E}$ upon the simulated global SST field, obtained from the periodically forced meltwater experiment (forcing period of $35 \mathrm{yr}$ ) for different lags expressed in terms of the phase in degrees of the 35-yr SSTA cycle in the North Atlantic. Units are K per standard deviation of multidecadal North Atlantic temperature anomalies. This figure can be directly compared with the reconstructed global multidecadal SST mode shown in Fig. 5 in Delworth and Mann (2000).

waves and hence the lag between Atlantic and Pacific may be strongly model dependent, the robustness of these results has to be studied using more comprehensive climate models.

This global teleconnection mechanism of North Atlantic THC changes and its possible impact on ENSO variability may also be the reason for the similarity of the periodicities of interdecadal "ENSO" amplitude modulations and meridional overturning variations in the North Atlantic as simulated in the GFDL R15 model (Delworth et al. 1993; Knutson et al. 1997), the ECHAM3/LSG model (Timmermann et al. 1998; Timmermann et al. 1999b), and the ECHAM4/OPYC model (Timmermann 2003).

\section{Conclusions}

We presented modeling evidence for an oceanic teleconnection that connects multidecadal- to millennial- scale thermocline anomalies in the North Atlantic with anomalies in the other ocean basins (Huang et al. 2000; Cessi et al. 2004; Johnson and Marshall 2004). Initially a freshwater anomaly in the North Atlantic triggers a collapse of the THC that is partly established by wave adjustments in the global oceans. A reduction of the Atlantic meridional overturning strength of about $20 \mathrm{~Sv}$ generates a thermocline anomaly near the Atlantic (A), Indian (I), and Pacific (P) eastern boundaries of about 50,30 , and $12 \mathrm{~m}$, respectively. This gives typical amplitude ratios for centennial time scales of $\mathrm{I} / \mathrm{A}=0.6, \mathrm{I} / \mathrm{P}=$ 0.4 , and $\mathrm{P} / \mathrm{A}=0.24$, in rough agreement with the theoretical results (see Fig. 2). The simulated IndianAtlantic amplitude ratio is smaller than expected from idealized theoretical considerations. This may be due to western boundary effects, the coarse resolution of our model, the use of a B-grid, and interactions with the Agulhas Current. Triggered thermocline anomalies in the Pacific (see Fig. 4) do not only have the effect of 
Strength of MOC [Sv]

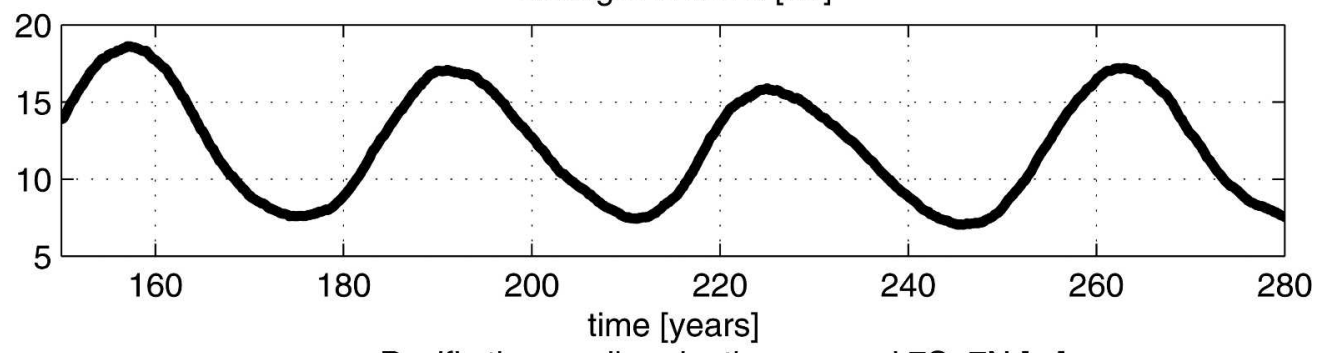

mean Pacific thermocline depth averaged 7S-7N [m]
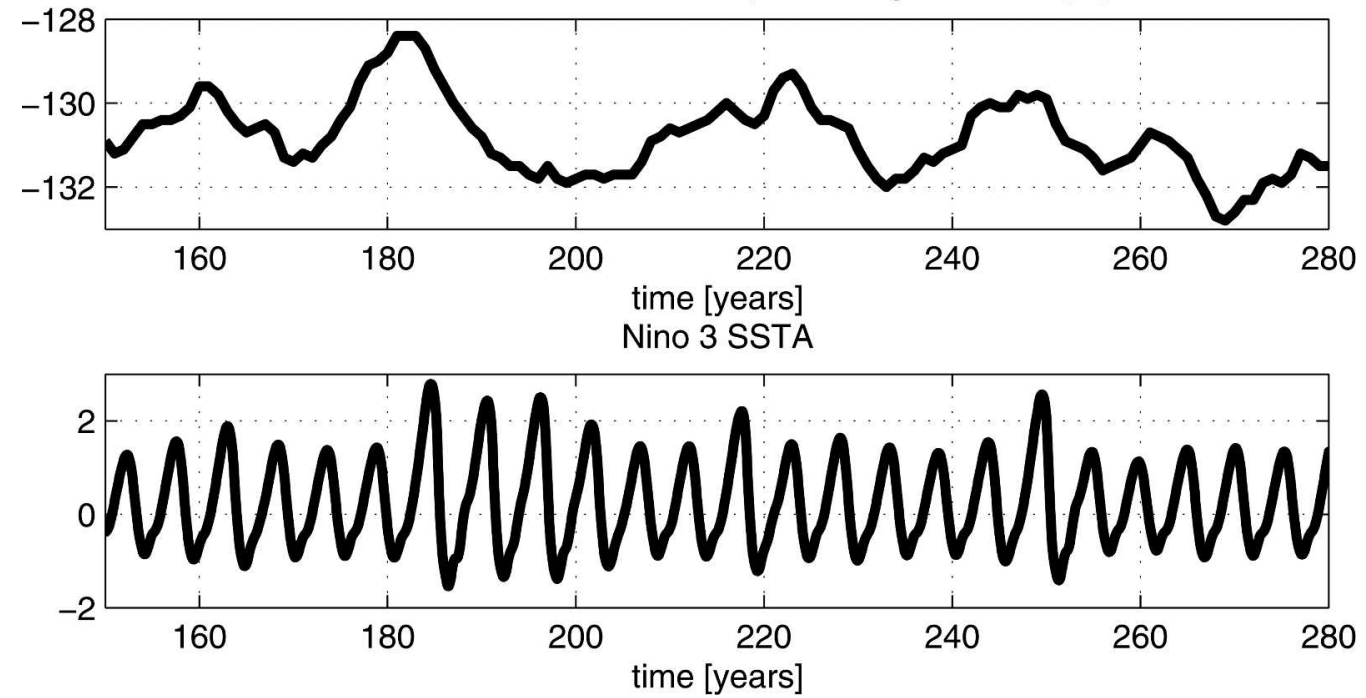

FIG. 11. (top) Simulated maximum strength of the meridional streamfunction in the North Atlantic (Sv) for a sinusoidal freshwater forcing with a period of $35 \mathrm{yr}$. The data are smoothed with a 9-yr running mean filter. The simulation is performed with the ECBILT-CLIO coupled model. (middle) Simulated mean depth of the $25-\sigma_{\theta}$ surface $(\mathrm{m})$ in the tropical Pacific averaged from $7^{\circ} \mathrm{S}$ to $7^{\circ} \mathrm{N}$, as simulated by ECBIILT-CLIO using periodic freshwater forcing. (bottom) Response of the Niño-3 SSTA (K) simulated by the intermediate ENSO model to the background state thermocline variations extracted from the periodic ECBILT-CLIO freshwater experiment described above. An air-sea coupling strength of 0.85 was used (standard is 1.0).

making the warm pool saltier due to geostrophic transport changes (Timmermann et al. 2005) but also weaken ENSO activity considerably, even in the selfsustained supercritical oscillation regime. These changes are due to an overall zonal mean deepening of the tropical thermocline in the Pacific.

Our analysis has mainly focused on the oceanic teleconnection, despite the large-scale atmospheric changes that are simulated in response to a THC collapse. These northern hemispheric wind changes (not shown) may also lead to centennial-scale changes of the thermocline depth. Further studies will disentangle the atmospheric and oceanic teleconnections in more detail. We have discussed only one controlling factor of Pacific thermocline changes (the remote effect due to global baroclinic ocean adjustment), while neglectingfor reasons of simplicity-the importance of wind changes in spinning up the ocean thermocline structure
(Boccaletti et al. 2004). Further studies will elucidate the importance of wind changes on the thermocline structure in the Pacific and hence on ENSO variability on multidecadal to millennial time scales.

A part of the Coupled Model Intercomparison Project-2 (CMIP-2) will focus on the forced response of the North Atlantic THC to freshwater perturbations. Water-hosing experiments will be performed with state-ofthe-art CGCMs. A way to verify or falsify our hypothesis of THC-ENSO connections would be to diagnose simulated ENSO amplitude changes in response to the prescribed freshwater forcing. Further support for our hypothesis may come from fossil tropical Pacific corals from the Younger Dryas Period. As shown in the previous sections, a THC shutdown leads to a significant damping of ENSO variations. This prediction may be testable in the near future using fossil coral data (Tudhope et al. 2001) or varved sediments (Rodbell et al. 
1999; Rittenour et al. 2000; Moy et al. 2002). Again thermocline seiching is not the only mechanism affecting ENSO variability on long time scales. Other effects that may have an effect on ENSO variability during the Younger Dryas include precessional forcing (Clement et al. 2001) and glacial boundary conditions (An et al. 2004).

Many details of the global seiching mechanism have not been fully understood, such as the competition between coastal shelf and Kelvin waves and the strong Agulhas Current or the role of higher-order vertical modes. Furthermore, large-scale mean temperature changes in the tropical Pacific feed back onto the salinity budget and the stability of the thermohaline circulation due to large-scale atmospheric reorganizations of the Pacific-Atlantic moisture transport (Schmittner et al. 2000). In our simulation, a decrease in ENSO variance during the THC shutdown phase leads to an averaged surface cooling of the eastern equatorial $\mathrm{Pa}$ cific that has to compete with a slight warming due to the deeper thermocline and reduced upwelling of cold waters. It is unclear whether in reality the net effect will be a cooling or warming. Hence, the subsequent negative or positive feedbacks onto the strength of the meridional overturning in the North Atlantic cannot be assessed here.

In addition to the impact of North Atlantic THC variations on ENSO, they may also influence the $\mathrm{Pa}$ cific decadal oscillation (PDO; see Figs. 2 and 10). In fact, the multidecadal SST pattern shown in Fig. 10 is not subjected to strong tropical air-sea coupling. A more realistic model may amplify the equatorial Pacific signal and generate a more symmetric meridional response in both hemispheres, which may eventually resemble the PDO pattern. How much remotely forced thermocline variations triggered by THC changes have contributed to the observed PDO variance remains unclear.

Acknowledgments. U. Krebs was supported from the Collaborative Research Project SFB460 of the Deutsche Forschungsgemeinschaft. A. Timmermann and S. I. An have been supported by the Japan Agency for Marine-Earth Science and Technology (JAMSTEC) through its sponsorship of the International Pacific Research Center. H. Goosse is a Research Associate with the Fonds National de la Récherche Scientifique (Belgium). We are grateful to Fei-Fei Jin and Luis Bejerano for developing the intermediate ENSO model and its linearized code and for providing it for our study. We thank Andreas Schmittner and two anonymous reviewers for their very constructive comments on the paper.

\section{REFERENCES}

An, S.-I., and F.-F. Jin, 2004: Nonlinearity and asymmetry of ENSO. J. Climate, 17, 2399-2412.

_ A. Timmermann, L. Bejerano, F.-F. Jin, F. Justino, Z. Liu, H. Goosse, and S. Tudhope, 2004: Modeling evidence for enhanced El Niño-Southern Oscillation amplitude during the Last Glacial Maximum. Paleoceanography, 19, PA4009, doi:10.1029/2004PA001020.

Battisti, D., 1988: The dynamics and thermodynamics of a warming event in a coupled tropical ocean-atmosphere model. $J$. Atmos. Sci., 45, 2889-2919.

Behl, R., and J. Kennett, 1996: Evidence for brief interstadial events in the Santa Barbara Basin, NE Pacific during the past 60 Kyr. Nature, 379, 243-246.

Bjerknes, J., 1969: Atmospheric teleconnections from the equatorial Pacific. Mon. Wea. Rev., 97, 163-172.

Blunier, T., and E. Brook, 2001: Timing of millennial-scale climate change in Antarctica and Greenland during the last glacial period. Science, 291, 109-112.

— land during the last glacial period. Nature, 394, 739-743.

Boccaletti, G., R. Pacanowski, S. Philander, and A. V. Fedorov, 2004: The thermal structure of the upper ocean. J. Phys. Oceanogr., 34, 888-902.

Boer, G., B. Yu, S. Kim, and G. Flato, 2004: Is there observational support for an El Niño-like pattern of future global warming. Geophys. Res. Lett., 31, L06201, doi:10.1029/2003GL018722.

Campin, J., and H. Goosse, 1999: A parameterization of dense overflow in large-scale ocean models in z coordinate. Tellus, 51A, 412-430.

Cessi, P., K. Bryan, and R. Zhang, 2004: Global seiching of thermocline waters between the Atlantic and the Indian-Pacific Ocean Basins. Geophys. Res. Lett., 31, L04302, doi:10.1029/ 2003 GL019091.

Clement, A., R. Seager, M. Cane, and S. Zebiak, 1996: An ocean dynamical thermostat. J. Climate, 9, 2190-2196.

,$- \ldots$, and $—$ 1999: Orbital controls on the tropical climate. Paleoceanography, 14, 441-456.

- M. A. Cane, and R. Seager, 2001: An orbitally driven tropical source for abrupt climate change. J. Climate, 14, 23692375.

Collins, M., 2000: Understanding uncertainties in the response of ENSO to greenhouse warming. Geophys. Res. Lett., 27, 35093513.

Crowley, T., and S. Baum, 1997: Effect of vegetation on an ice-age climate model simulation. J. Geophys. Res., 102, $16463-$ 16480 .

Dansgaard, W., and Coauthors, 1993: Evidence for general instability of past climate from a $250 \mathrm{kyr}$ ice-core record. Nature, 364, 218-220.

Delworth, T., and M. Mann, 2000: Observed and simulated multidecadal variability in the northern hemisphere. Climate Dyn., 16, 661-676.

_, S. Manabe, and R. Stouffer, 1993: Interdecadal variations of the thermohaline circulation in a coupled ocean-atmosphere model. J. Climate, 6, 1900-1989.

Dickson, B., I. Yashayaev, J. Meincke, B. Turrell, S. Dye, and J. Holfort, 2002: Rapid freshening of the deep North Atlantic Ocean over the past four decades. Nature, 416, 832-837.

Dong, B., and R. Sutton, 2002: Adjustment of the coupled oceanatmosphere system to a sudden change in the Thermohaline 
Circulation. Geophys. Res. Lett., 29, 1728, doi:10.129/ 2002GL015229.

Döscher, R., C. W. Böning, and P. Herrmann, 1994: Response of circulation and heat transport in the North Atlantic to changes in thermohaline forcing in northern latitudes: A model study. J. Phys. Oceanogr., 24, 2306-2320.

Fu, R., A. D. Genio, W. Rossow, and W. Liu, 1992: Cirrus-cloud thermostat for the tropical sea surface temperatures tested using satellite data. Nature, 358, 394-397.

Gent, P., and J. McWilliams, 1990: Isopycnal mixing in ocean general circulation models. J. Phys. Oceanogr., 20, 150-155.

Gill, A., 1980: Some simple solutions for heat induced tropical circulation. Quart. J. Roy. Meteor. Soc., 106, 447-462.

Goodman, P. J., 2001: Thermohaline adjustment and advection in an OGCM. J. Phys. Oceanogr., 31, 1477-1497.

Goosse, H., and T. Fichefet, 1999: Importance of ice-ocean interactions for the global ocean circulation: A model study. $J$. Geophys. Res., 104 (C10), 23 337-23 355.

— E. Eeleersnijder, T. Fichefet, and M. England, 1999: Sensitivity of a global coupled ocean-sea ice model to the parameterization of vertical mixing. J. Geophys. Res., 104 (C6), 13 681-13 695.

Hartmann, D., and M. Michelsen, 1993: Large-scale effects on the regulation of tropical sea surface temperature. J. Climate, $\mathbf{6}$, 2049-2062.

Heinrich, H., 1988: Origin and consequences of cyclic ice rafting in the northeast Atlantic Ocean during the past 130000 years. Quat. Res., 29, 142-152.

Held, I., and M. Suarez, 1978: A two-level primitive equation atmosphere model designed for climate sensitivity experiments. J. Atmos. Sci., 35, 206-229.

Houghton, J. T., Y. Ding, D. J. Griggs, M. Noguer, P. J. van der Linden, X. Dai, K. Maskell, and C. A. Johnson, Eds., 2001: Climate Change 2001: The Scientific Basis. Cambridge University Press, $881 \mathrm{pp}$.

Hsieh, W., and K. Bryan, 1996: Redistribution of sea level rise associated with enhanced greenhouse warming: A simple model study. Climate Dyn., 12, 535-544.

—, M. K. Davey, and R. Wajsowicz, 1983: The free Kelvin wave in finite-difference numerical models. J. Phys. Oceanogr., 13, 1381-1397.

Huang, R., M. Cane, N. Naik, and P. Goodman, 2000: Global adjustment of the thermocline in response to deepwater formation. Geophys. Res. Lett., 27, 759-762.

Jin, F.-F., 1997: An equatorial ocean recharge paradigm for ENSO. Part I: Conceptual model. J. Atmos. Sci., 54, 811-829.

—, S.-I. An, A. Timmermann, and X. Zhang, 2003: Strong El Niño events and nonlinear dynamic heating. Geophys. Res. Lett., 30, 1120, doi:10.1029/2002GL016356.

Johnson, H. L., and D. P. Marshall, 2002: A theory for the surface Atlantic response to thermohaline variability. J. Phys. Oceanogr., 32, 1121-1132.

— , and - 2004: Global teleconnections of meridional overturning circulation anomalies. J. Phys. Oceanogr., 34, 17021722.

Kawase, M., 1987: Establishment of deep ocean circulation driven by deep water production. J. Phys. Oceanogr., 17, 2294-2317.

Knutson, T., S. Manabe, and D.-F. Gu, 1997: Simulated ENSO in a global coupled ocean-atmosphere model: Multidecadal amplitude modulation and $\mathrm{CO}_{2}$ sensitivity. J. Climate, 10, 138161.

Knutti, R., J. Flückiger, T. Stocker, and A. Timmermann, 2004:
Strong hemispheric coupling of glacial climate through freshwater discharge and ocean circulation. Nature, 430, 851-856.

Kushnir, Y., 1994: Interdecadal variations in the North Atlantic sea surface temperature and associated atmospheric conditions. J. Climate, 7, 141-157.

Latif, M., E. Roeckner, U. Mikolajewicz, and R. Voss, 2000: Tropical stabilization of the thermohaline circulation in a greenhouse warming simulation. J. Climate, 13, 1809-1813.

Liu, Z., 2002a: A simple model study of the forced response of ENSO to an external periodic forcing. J. Climate, 15, 10881098.

, 2002b: How long is the memory for tropical ocean dynamics? J. Climate, 15, 3518-3522.

Mann, M., and J. Park, 1994: Global scale modes of surface temperature variability on interannual to century time scales. $J$. Geophys. Res., 99, 25 819-25 833.

— - - and R. Bradley, 1995: Global interdecadal and century-scale climate oscillations during the past five centuries. Nature, 378, 266-270.

Marshall, J., and F. Molteni, 1993: Toward a dynamic understanding of planetary-scale flow regimes. J. Atmos. Sci., 50, 1792 1818.

Meehl, G., J. Arblaster, and W. Strand, 1998: Global scale decadal climate variability. Geophys. Res. Lett., 25, 3983-3986. , P. Gent, J. Arblaster, B. Otto-Bliesner, E. Brady, and A. Craig, 2001: Factors that affect the amplitude of El Niño in global coupled models. Climate Dyn., 17, 515-527.

Mellor, G., and T. Yamada, 1982: Development of a turbulence closure model for geophysical fluid problems. Rev. Geophys. Space Phys., 20, 851-875.

Mesinger, F., and A. Arakawa, 1976: Numerical methods used in atmospheric models. Tech. Rep., World Meteorological Organization, GARP Publication Series 17, 64 pp.

Miller, R., 1997: Tropical thermostats and low cloud cover. $J$. Climate, 10, 409-440.

Moy, C. M., G. O. Seltzer, D. T. Rodbell, and D. Anderson, 2002: Variability of El Niño/Southern Oscillation activity at millennial timescales during the Holocene epoch. Nature, 420, 162 165.

Mysak, L., 1980: Recent advances in shelf wave dynamics. Rev. Geophys. Space Phys., 18, 211-241.

Opsteegh, J., R. Haarsma, F. Selten, and A. Kattenberg, 1998: ECBILT: A dynamic alternative to mixed boundary conditions in ocean models. Tellus, 50A, 348-367.

Peltier, W., 1994: Ice age paleotopography. Science, 265, 195-201.

Pierrehumbert, R., 1995: Thermostats, radiator fins, and the runaway greenhouse. J. Atmos. Sci., 52, 1784-1806.

Ramanathan, W., and V. Collins, 1992: Thermostat and global warming. Nature, 357, 649.

Rittenour, T. M., J. Brighan-Grette, and M. Mann, 2000: El Niñolike climate teleconnection in New England during the Late Pleistocene. Science, 288, 1039-1042.

Rodbell, D., G. Seltzer, D. Anderson, M. Abbott, D. Enfield, and J. Newman, 1999: An 15000-year record of El Niño-driven alluviation in southwestern Ecuador. Science, 283, 516-520.

Saenko, O. A., A. Schmittner, and A. J. Weaver, 2004: The Atlantic-Pacific seesaw. J. Climate, 17, 2033-2038.

Schmittner, A., C. Appenzeller, and T. Stocker, 2000: Enhanced Atlantic freshwater export during El Niño. Geophys. Res. Lett., 27, 1163-1166.

, O. A. Saenko, and A. J. Weaver, 2003: Coupling of the hemispheres in observations and simulations of glacial climate change. Quart. Sci. Rev., 22, 659-671. 
Schultz, H., U. von Rad, and H. Erlenkeuser, 1998: Correlation between Arabian Sea and Greenland climate oscillations of the past 110,000 years. Nature, 393, 54-57.

Stocker, T. F., and S. Johnsen, 2003: A minimum thermodynamic model for the bipolar seesaw. Paleoceanography, 18, 1087, doi:10.1029/2003PA000920.

Stott, L., C. Poulsen, S. Lund, and R. Thuell, 2002: Super ENSO and global climate oscillations at millenial time scales. Science, 297, 222-226.

Suginohara, N., and M. Fuakasawa, 1988: Set-up of the deep circulation in multilevel numerical models. J. Oceanogr. Soc. Japan, 44, 315-336.

Sun, D. Z., 2003: A possible effect of an increase in the warm-pool SST on the magnitude of El Niño warming. J. Climate, 16, 185-205.

- and Z. Liu, 1996: Dynamic ocean-atmosphere coupling: A thermostat for the tropics. Science, 272, 1148-1150.

Timmermann, A., 2003: Decadal ENSO amplitude modulations: A nonlinear mechanism. Global Planet. Changes, 37, 135156.

, and F.-F. Jin, 2004: Intensification of the annual cycle in the tropical Pacific due to greenhouse warming. Geophys. Res. Lett., 31, L12208, doi:10.1029/2004GL019442.

, M. Latif, R. Voss, and A. Grötzner, 1998: Northern Hemi- spheric interdecadal variability: A coupled air-sea mode. $J$. Climate, 11, 1906-1931.

- — - A. Bacher, J. Oberhuber, and E. Roeckner, 1999a: Increased El Niño frequency in a climate model forced by future greenhouse warming. Nature, 398, 694-696.

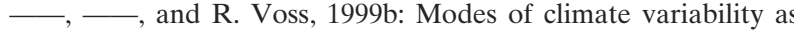
simulated by the coupled atmosphere-ocean model ECHAM3/LSG, Part I: ENSO-like climate variability and its low-frequency modulation. Climate Dyn., 15, 605-618.

_ , F. Justino, F.-F. Jin, U. Krebs, and H. Goosse, 2004: Surface temperature control in the North and tropical Pacific during the last glacial maximum. Climate Dyn., 23, 353-370.

— U. Krebs, F. Justino, and H. Goosse, 2005: Mechanisms for millennial-scale global synchronization during the last glacial period. Paleoceanography, in press.

Trefethen, L. N., 1999: Computation of pseudospectra. Acta Numerica, 8, 247-295.

Tudhope, A., and Coauthors, 2001: Variability in the El NiñoSouthern Oscillation through a glacial-interglacial cycle. Science, 291, 1511-1517.

Wajsowicz, R., 1986: Free planetary waves in finite-difference numerical models. J. Phys. Oceanogr., 16, 773-789.

Zebiak, S. E., and M. A. Cane, 1987: A model El Niño-Southern Oscillation. Mon. Wea. Rev., 115, 2262-2278. 